\title{
Comparative Stratification of Cardiovascular Risk through Framingham and Globo Risk in Patients with Psoriasis of IAHULA November 2017-May 2018.
}

\author{
José Sampayo ${ }^{1 *}$, Luis Dulcey², Camilo Cazorla ${ }^{3}$, Héctor Moreno ${ }^{4}$, Nohemi Molina ${ }^{5}$, Diana Villamizar ${ }^{6}$, Louis Soucre ${ }^{7}$ \\ and Raimondo Caltagirone ${ }^{8}$
}

${ }^{1-4}$ Internal Medicine Residents ULA Mérida, Venezuela

${ }^{5}$ ULA Mérida Undergraduate Student, Venezuela

${ }^{6}$ Specialist in Physiatry ULA Mérida, Venezuela

${ }^{7}$ Specialist in Dermatology ULA Mérida, Venezuela

${ }^{8}$ Specialist in Internal Medicine Critical Care ULA Mérida, Venezuela

*Corresponding author: Jose Jorge Sampayo, Internal Medicine Residents ULA Mérida, Venezuela

\begin{abstract}
Objectives: To know the frequency of Metabolic Syndrome in patients with Psoriasis who come to the consultation of the Dermatology Service of the Autonomous University Hospital of the Andes November 2017 to May 2018.

Materials and Methods: Observational analytical descriptive study. Patients with Psoriasis diagnoses who attended the dermatology office were selected, PASI, ATP-III, Framingham and GLOBORISK were applied.

Results: 55 patients, 55\% men and 45\% women, there was statistical correlation between older age groups and PASI index $(\mathrm{p}=0.023)$. The main modifiable cardiovascular risk factors were smoking, sedentary lifestyle and obesity, statistical correlation was found for sedentary lifestyle ( $\mathrm{p}=0.047)$. The main non-modifiable cardiovascular risk factors were Hypertension and Diabetes showing both statistical significance $(\mathrm{p}=0.004),(\mathrm{p}=0.0001)$. The ATP-III criteria showed statistical significance for Hypertension, glycemia, total cholesterol and low HDL ( $p=0.003, p=0.008, p=0.027, p=0.017)$. The frequency of metabolic syndrome represented $47.27 \%$ of the sample. The most affected gender was male (61.54\%). Statistical correlation was found in the older age groups for the presence of Metabolic Syndrome ( $\mathrm{p}=0.0001)$. The group with the highest frequency of metabolic syndrome was the one with 6 to 10 years of the disease $(\mathrm{p}=0.001)$. When applying the Framingham and GLOBORISK scores, there were higher scores in the patients as PASI was increased.
\end{abstract}

Conclusion: There is a higher frequency of Metabolic Syndrome in patients with Psoriasis, so it is recommended to establish measures aimed at reducing the burden of cardiovascular disease in these patients.

Keywords: Psoriasis; Metabolic Syndrome; Risk; Severity Index of the Disease

\section{Introduction}

Psoriasis has evolved conceptually over time, from being considered a skin disease in its first descriptions, currently we can define it as a chronic and inflammatory skin disease, without a defined, genetically determined, pathophysiologically autoimmune etiology, of intermittent evolution, at risk of skin, systemic and psychological comorbidities, which impact on quality of life [1]. The most characteristic feature of psoriasis is the hyperproliferation and altered differentiation of keratinocytes, in addition to immune, biochemical, and vascular abnormalities influenced by multiple environmental factors that can trigger or exacerbate its evolution, 
affecting between 2 and 3\% of the population. World [2]. Psoriasis is estimated to affect approximately more than 125 million people worldwide, with a global prevalence of $2-3 \%$. Being greater in those of Caucasian origin, it is variable in other races and exceptional among the indigenous people of the American continent and Australia. The white race has a prevalence of $0.1 \%$ and the incidence in the black race is low. In Germany there is a prevalence of the disease of $1.7 \%$, in Sweden of 2.3\%, the United States 2.1\%, India $0.7 \%$, Japan $0.5 \%$. In Latin American countries it is working on it. Studies suggest that the prevalence in South America is 1\% [3].

According to the global report of psoriasis published by the WHO in 2016, people with psoriasis are at high risk of suffering from various comorbid conditions, such as cardiovascular disease, diabetes, obesity, Crohn's disease, myocardial infarction, ulcerative colitis, metabolic syndrome, strokes or liver disease. Patients with moderate/severe psoriasis, especially in the 4th decade of life, have an increased risk of having a heart attack and survival decreases 3 years for men and 4 years for women because of cardiovascular events [4]. Epidemiological studies have aroused great interest in the association of psoriasis with different cardiovascular, metabolic and immune comorbidities with which it shares inflammatory pathways or a common background [5], however, its association with metabolic syndrome has been increasingly recognized [6]. Metabolic Syndrome (MS) is a set of cardiometabolic risk factors that confer a higher risk of developing cardiovascular disease than that attributed to each component in isolation. It affects approximately 15 to $25 \%$ of the general population, its prevalence is increasing both in developed countries (United States and European countries) and in developing countries, accompanying the increase in obesity globally $[7,8]$. Metabolic Syndrome confers a significant burden of disease, for example, some studies show that MS confers twice the risk of coronary artery disease, [9] as well as increases the risk of cerebrovascular disease, fatty liver and certain types of malignancies such as lymphomas and squamous cell carcinomas [10].

Current recommendations suggest that patients with psoriasis should be evaluated to rule out the presence of MS, and if it is present, they should receive intensive treatment, with interventions in their lifestyle, weight loss, control of blood pressure, diabetes, and hypercholesterolemia [11]. There are multiple criteria used to define metabolic syndrome at an international Mildl, those proposed by the International Diabetes Foundation (IDF), those of the National Cholesterol Education Program Adult Treatment Panel III (NCEP ATP III) and others such as those of the Organization World Health Organization (WHO) and the American Association of Clinical Endocrinologists (AACE) that have in common grouping a series of abnormalities in the same individual [12-14].

It should be noted that most of the research papers use the ATP III criteria to compare results due to their practical utility; associating simplicity to carry out laboratory tests; and it also requires complying with three of the five parameters. There is evidence that this association (SM/PSORIASIS) is due to increased T cell immune activity, and increased production of tumor necrosis factor alpha. These classify psoriasis as the prototype of an inflammatory disease characterized by TH1 and TH17 activation, whose cytokines such as IL1, IL6, and tumor necrosis factor alpha are elevated in blood and skin mediators that could have an effect on adipogenesis, lipid metabolism, and insulin signaling. Hence, the entire inflammatory process in psoriasis has a great impact on obesity, diabetes, thrombosis, and arteriosclerosis, which, in turn, can influence the pathogenesis of psoriasis by promoting the proinflammatory state and increasing the propensity to develop the syndrome. Metabolic [15-17].

Given that Psoriasis is one of the main reasons for consultation in the dermatological area, and having no current data on the incidence of MS in Venezuela, it is necessary to establish the prevalence of MS in patients with Psoriasis and subsequently establish if there is a correlation between both pathologies. It is important to highlight that in the autonomous institute university hospital of the Andes edo. Merida Venezuela no research work has been carried out that has determined the cardiovascular risk profile or the frequency of metabolic syndrome in patients with Psoriasis who come to the Dermatology service consultation of said institution, therefore an observational study of cross section in the period established from November 2017 to May 2018. It will be of great contribution and serve as health information, in addition to contributing to the prevention of said pathology and thus reducing morbidity and mortality. The motivation to carry out this study arises; and in turn, to instill future generations to continue the present investigation.

\section{Objectives}

\section{General}

Stratification of cardiovascular risk using the Framingham and Globorisk scores in patients with Psoriasis who come to the Dermatology service consultation of the Autonomous Institute University Hospital of the Andes during the period from November 2017 to May 2018.

\section{Specific}

a. Know the demographic characteristics of the study population.

b. Describe the degree of severity of psoriasis lesions, according to the area index and severity of psoriasis (PASI).

c. Identify the Cardiovascular Risk factors in Psoriasis patients who come to the Dermatology service consultation at the Autonomous Institute Hospital Universitario de los Andes. 
d. Identify the presence of the components of the metabolic syndrome, according to the ATP III criteria.

e. Establish statistical correlation between time of evolution of psoriasis, PASI index and SM.

f. Estimate cardiovascular risk according to the Framingham and GLOBORISK scales.

g. Establish correlation between cardiovascular risk/ psoriasis and metabolic syndrome/psoriasis.

\section{Study design}

Descriptive analytical observational study.

\section{Population and sample}

All patients who attended during the period from November 1 , 2017 to May 31, 2018, with diagnoses of Psoriasis of both genders who attended the dermatology consultation of the Autonomous Institute Hospital Universitario de los Andes, and who met the inclusion criteria.

\section{The inclusion criteria were as follows}
a. Patients of both genders over 18 years of age.
b. Patients with a diagnosis of Psoriasis.
c. Informed consent signature.

\section{Exclusion criteria}

a. Immunological diseases, others.

b. Mixed connective tissue disease

c. Stage IV-V Chronic Kidney Disease

d. Neoplasm diagnosed.

e. Infectious processes in any form of presentation.

\section{Data processing and analysis}

Quantitative data were presented with measures of central tendency and dispersion (mean and standard deviation); the qualitative data were presented with absolute and relative frequencies (in percentages). The statistical association of qualitative data (bivariate analysis) was evaluated using the chisquare test, the statistical differences of quantitative data were evaluated using the Student's t-test or ANOVA. The agreement between the Globo Risk and Framingham scales was evaluated through a Bland-Altman graph. Statistical significance was considered for values of $\mathrm{p}<0.05$. Statistical analyzes and graphs were performed using SPSS version 21 (IBM Corporation, New York, US), Excel 2010 (Microsoft Corporation, Redmond, US) and GraphPad Prism version 5 (GraphPad Software Inc, La Jolla, USA).

\section{Ethical component}

The ethical components of this research work will be carried out based on the international ethical standards set forth in the Declaration of Helsinki [18] and that contemplated in the Code of Medical Deontology of the Venezuelan Medical Federation of March 20, 1985, in its Title V, Chapter 4, referring to research in human beings. It was requested to fill out the informed consent to the patients or their legal representatives when they are disabled, explaining in detail the purpose of the study; Likewise, the risk of complications that could arise with the taking of the sample, the confidentiality of the data obtained, the academic purposes and the non-intervention of the investigator in the treatment, as well as in the clinical evolution of the patient, will be explained. The economic resources for the realization of this study will be provided mostly by the author. This study has the support of the Autonomous Institute of the University Hospital of the Andes (IAHULA), the Multidisciplinary Laboratory of Clinical-Epidemiological Research (Lab-MICE) of IAHULA, the Department of Internal Medicine, the Dermatology department of IAHULA.

\section{Results}

Table 1 showed that the study sample was made up of 55 patients who attended the IAHULA Dermatology clinic, distributed by gender as follows; female gender $n=25$ with a respective percentage of $(45.5 \%)$ and the highest proportion male gender $\mathrm{n}=30(54.5 \%)$. The patients were stratified according to the PASI classification in 4 categories; inactive or asymptomatic forms, Mild, Moderate, and finally the severe and very severe forms in the last group as a last category to simplify their subsequent analysis. It was evidenced that the Moderate form of the disease according to the PASI index was the one with the highest frequency $n=22$, with a gender distribution of 10 (45.5\%) for the female and 12 (55.5) for the gender. male. Regarding age groups, they were divided into 4 categories: those under 30 years, between 31 to 50 years, 51 to 60 years, and those over 60 years, respectively. The highest proportion of patients corresponded to the group over 60 years old (16), secondly those between 31 and 50 years old (14), thirdly between 51 and 60 years old (13) and lastly those under 30 years old (12) this correlation between the age of the patients and the PASI index being statistically significant. 
Table 1: Sociodemographic characteristics and PASI index of the evaluated patients discriminated by the severity of Psoriasis.

\begin{tabular}{|c|c|c|c|c|c|}
\hline & \multicolumn{4}{|c|}{ Psoriasis (Index of PASI) } & \multirow{3}{*}{$\begin{array}{l}\text { Total } \\
\mathrm{n}=55\end{array}$} \\
\hline & \multirow{2}{*}{$\begin{array}{c}\text { Inactive } \\
\mathrm{n}=10\end{array}$} & \multirow{2}{*}{$\begin{array}{l}\text { Mild } \\
\mathrm{n}=17\end{array}$} & \multirow{2}{*}{$\begin{array}{c}\text { Moderate } \\
\mathrm{n}=22\end{array}$} & \multirow{2}{*}{$\begin{array}{c}\text { Severe and very severe } \\
n=6\end{array}$} & \\
\hline & & & & & \\
\hline Sex & \multicolumn{5}{|c|}{$p=0,138$} \\
\hline \multirow[t]{2}{*}{ Women } & 3 & 11 & 10 & 1 & 25 \\
\hline & $(30 \%)$ & $(64,7 \%)$ & $(45,5 \%)$ & $(16,7 \%)$ & $(45,5 \%)$ \\
\hline \multirow[t]{2}{*}{ Men } & 7 & 6 & 12 & 5 & 30 \\
\hline & $(70 \%)$ & $(35,3 \%)$ & $(54,5 \%)$ & $(83,3 \%)$ & $(54,5 \%)$ \\
\hline Age (Years) & \multicolumn{5}{|c|}{$p=0,023$} \\
\hline \multirow[t]{2}{*}{ Average* } & $40 \pm 15$ & $37 \pm 19$ & $60 \pm 11$ & $56 \pm 18$ & $49 \pm 18$ \\
\hline & $(20-63)$ & $(15-75)$ & $(32-77)$ & $(29-77)$ & $(15-77)$ \\
\hline \multirow[t]{2}{*}{$\leq 30$} & 4 & 7 & - & 1 & 12 \\
\hline & $(40 \%)$ & $(41,2 \%)$ & & $(16,7 \%)$ & $(21,8 \%)$ \\
\hline \multirow[t]{2}{*}{$31-50$} & 3 & 6 & 4 & 1 & 14 \\
\hline & $(30 \%)$ & $(35,3 \%)$ & $(18,2 \%)$ & $(16,7 \%)$ & $(25,5 \%)$ \\
\hline \multirow[t]{2}{*}{$51-60$} & 2 & 2 & 8 & 1 & 13 \\
\hline & $(20 \%)$ & $(11,8 \%)$ & $(36,4 \%)$ & $(16,7 \%)$ & $(23,6 \%)$ \\
\hline \multirow[t]{2}{*}{$>60$} & 1 & 2 & 10 & 3 & 16 \\
\hline & $(10 \%)$ & $(11,8 \%)$ & $(45,5 \%)$ & $(50 \%)$ & $(29,1 \%)$ \\
\hline Graffar & \multicolumn{5}{|c|}{$p=0,486$} \\
\hline \multirow[t]{2}{*}{ I } & 1 & 1 & - & - & 2 \\
\hline & $(10)$ & $(5,9)$ & & & $(3,6)$ \\
\hline \multirow[t]{2}{*}{ II } & 2 & 4 & 2 & 2 & 10 \\
\hline & (20) & $(23,5)$ & $(9,1)$ & $(33,3)$ & $(18,2)$ \\
\hline \multirow[t]{2}{*}{ III } & 3 & 4 & 5 & 3 & 15 \\
\hline & (30) & $(23,5)$ & $(22,7)$ & -50 & $(27,3)$ \\
\hline \multirow[t]{2}{*}{ IV } & 4 & 6 & 9 & 1 & 20 \\
\hline & $(40)$ & $(35,3)$ & $(40,9)$ & $(16,7)$ & $(36,4)$ \\
\hline \multirow[t]{2}{*}{$\mathrm{V}$} & - & 2 & 6 & - & 8 \\
\hline & & $(11,8)$ & $(27,3)$ & & $(14,5)$ \\
\hline
\end{tabular}

In relation to the Graffar, the distribution was made based on 5 categories where it was observed that the groups with the highest frequency corresponded to IV n=20 (36.4) and III n=15 (27.3). Table 2 shows the modifiable cardiovascular risk factors identified in the patients in the study. They were stratified into 5 categories defined as Sedentary, Obesity, Smoker High fat diet and Dyslipidemia, of which the most frequent corresponded to Smoker with $34.5 \% \mathrm{n}=19$ patients, in second place Sedentary, third place Obesity, in fourth place Dyslipidemia and as less frequent of the 5 the presence of Dyslipidemia. Table 3 shows those modifiable cardiovascular risk factors distributed in 3 categories; Hypertension, diabetes mellitus and Myocardial infarction, the first 2 were statistically significant as they were correlated with the severity of psoriasis, but the presence of Myocardial infarction was not.

Table 2: Modifiable cardiovascular risk factors in the evaluated patients discriminated by the severity of Psoriasis.

\begin{tabular}{|c|c|c|c|c|c|}
\hline \multirow[t]{2}{*}{ Variable } & \multicolumn{4}{|c|}{ Psoriasis (PASI Index) } & \multirow{2}{*}{$\begin{array}{l}\text { Total } \\
\mathrm{n}=55\end{array}$} \\
\hline & Inactive & Mild & Moderate & Severe and very severe & \\
\hline & $\mathrm{n}=10$ & $\mathrm{n}=17$ & $n=22$ & $n=6$ & \\
\hline Sedentary & \multicolumn{5}{|c|}{$p=0,047$} \\
\hline \multirow{2}{*}{$\mathrm{Si}$} & 2 & 3 & 12 & 1 & 18 \\
\hline & $(20 \%)$ & $(17,6 \%)$ & $(54,5 \%)$ & $(16,7 \%)$ & $(32,7 \%)$ \\
\hline \multirow{2}{*}{ No } & 8 & 14 & 10 & 5 & 37 \\
\hline & $(80 \%)$ & $(82,4 \%)$ & $(45,5 \%)$ & $(83,3 \%)$ & $(67,3 \%)$ \\
\hline
\end{tabular}




\begin{tabular}{|c|c|c|c|c|c|}
\hline Obesity & \multicolumn{5}{|c|}{$p=0,217$} \\
\hline \multirow{2}{*}{$\mathrm{Si}$} & 1 & 3 & 7 & - & 11 \\
\hline & $(10 \%)$ & $(17,6 \%)$ & $(31,85 \%)$ & & $(20,4 \%)$ \\
\hline \multirow{2}{*}{ No } & 9 & 14 & 15 & 6 & 44 \\
\hline & $(90 \%)$ & $(82,4 \%)$ & $(68,18 \%)$ & $(100 \%)$ & $(79,6 \%)$ \\
\hline Smoker & \multicolumn{5}{|c|}{$p=0,005$} \\
\hline \multirow{2}{*}{$\mathrm{Si}$} & 1 & 2 & 13 & 3 & 19 \\
\hline & $(10 \%)$ & $(11,8 \%)$ & $(59,1 \%)$ & $(50 \%)$ & $(34,5 \%)$ \\
\hline \multirow{2}{*}{ No } & 9 & 15 & 9 & 3 & 36 \\
\hline & $(90 \%)$ & $(88,2 \%)$ & $(40,9 \%)$ & $(50 \%)$ & $(65,5 \%)$ \\
\hline High fat diet & \multicolumn{5}{|c|}{$p=0,866$} \\
\hline \multirow{2}{*}{$\mathrm{Si}$} & 1 & 1 & 1 & - & 3 \\
\hline & $(10 \%)$ & $(5,9 \%)$ & $(4.50 \%)$ & & $(5,7 \%)$ \\
\hline \multirow{2}{*}{ No } & 9 & 16 & 21 & 6 & 52 \\
\hline & $(90 \%)$ & $(94,1 \%)$ & $(95.45 \%)$ & $(100)$ & $(94,3 \%)$ \\
\hline Dyslipidemia & \multicolumn{5}{|c|}{$p=0,687$} \\
\hline \multirow{2}{*}{$\mathrm{Si}$} & 1 & 1 & 3 & - & 6 \\
\hline & $(10)$ & $(5,9)$ & $(13,64)$ & & $(9,3)$ \\
\hline \multirow{2}{*}{ No } & 9 & 16 & 19 & 6 & 49 \\
\hline & $(90)$ & $(94,1)$ & $(86,56)$ & $(100)$ & $(90,7)$ \\
\hline
\end{tabular}

Table 3: Non-modifiable cardiovascular risk factors in the evaluated patients discriminated by the severity of Psoriasis.

\begin{tabular}{|c|c|c|c|c|c|}
\hline $\begin{array}{l}\text { Variables } \\
\text { (Comorbidities) }\end{array}$ & \multicolumn{4}{|c|}{ Psoriasis (PASI Index) } & \multirow{2}{*}{$\begin{array}{l}\text { Total } \\
\mathrm{n}=55\end{array}$} \\
\hline & Inactive & Mild & Moderate & Severe and very severe & \\
\hline & $\mathrm{n}=10$ & $\mathrm{n}=17$ & $\mathrm{n}=22$ & $n=6$ & \\
\hline Hypertension & \multicolumn{5}{|c|}{$p=0,004$} \\
\hline \multirow{2}{*}{ Yes } & 1 & 1 & 12 & 2 & 16 \\
\hline & $(10 \%)$ & $(5,9 \%)$ & $(54,5 \%)$ & $(33,3 \%)$ & $(29,1 \%)$ \\
\hline \multirow{2}{*}{ No } & 9 & 16 & 10 & 4 & 39 \\
\hline & $(90 \%)$ & $(94,1 \%)$ & $(45,5 \%)$ & $(66,7 \%)$ & $(70,9 \%)$ \\
\hline Diabetes mellitus & \multicolumn{5}{|c|}{$p=0,0001$} \\
\hline \multirow{2}{*}{ Yes } & - & - & 4 & 4 & 8 \\
\hline & & & $(18.19 \%)$ & $(66,7 \%)$ & $(14,55 \%)$ \\
\hline \multirow{2}{*}{ No } & 10 & 17 & 18 & 2 & 47 \\
\hline & $(100 \%)$ & $(100 \%)$ & $(81.81 \%)$ & $(33,3 \%)$ & $(85,45 \%)$ \\
\hline Myocardial infarction & \multicolumn{5}{|c|}{$p=0,172$} \\
\hline \multirow{2}{*}{ Yes } & - & - & 3 & - & 4 \\
\hline & & & $(13,64)$ & & $(5,6)$ \\
\hline \multirow{2}{*}{ No } & 10 & 17 & 19 & 6 & 51 \\
\hline & $(100 \%)$ & $(100 \%)$ & $(86,36 \%)$ & $(100 \%)$ & $(94,4 \%)$ \\
\hline
\end{tabular}

Table 4 shows the ATP-III criteria, applied to our study to define metabolic syndrome. The most frequent corresponded to Arterial Hypertension, the second was hypertriglyceridemia and the third had low HDL levels. Statistical significance was not seen in the Body Mass Index, Abdominal Circumference, and Triglycerides categories. In Table 5 it was observed that the frequency of metabolic syndrome represented $47.27 \%$ (26) of the sample. Regarding distribution, the most affected gender was male (61.54\%), $n=16$ of the 26 patients in our study. In the distribution by age, a higher proportion could be seen for the group of those over 60 years old, $n=13$ (50\%), finding a statistical correlation for the variables older age and the presence of metabolic syndrome in patients with Psoriasis. Table 6 corresponds to the crossing of data between the risk scales used in the study and the PASI of the patients, the 4 PASI categories previously indicated and the corresponding scores for Globorisk and Framingham were used. 10-year cardiovascular risk scores. A directly proportional relationship was observed as the PASI increased, the cardiovascular risk at 10 years increased for both scales. 
Table 4: ATP III criteria evaluated and discriminated by the severity of Psoriasis.

\begin{tabular}{|c|c|c|c|c|c|}
\hline & \multicolumn{4}{|c|}{ Psoriasis (PASI Index) } & \multirow{2}{*}{$\begin{array}{l}\text { Total } \\
\mathrm{n}=55\end{array}$} \\
\hline & Inactive & Mild & Moderate & Severe and very severe & \\
\hline & $\mathrm{n}=10$ & $\mathrm{n}=17$ & $\mathrm{n}=22$ & $\mathrm{n}=6$ & \\
\hline BMI & \multicolumn{5}{|c|}{$p=0,157$} \\
\hline High & $1(10 \%)$ & $2(12,5 \%)$ & $7(33,3 \%)$ & - & $10(18,9 \%)$ \\
\hline Normal & $9(90 \%)$ & $15(87,5 \%)$ & $15(66,7 \%)$ & $6(100 \%)$ & $45(81,1 \%)$ \\
\hline Arterial Pressure & \multicolumn{5}{|c|}{$p=0,003$} \\
\hline High & $1(10 \%)$ & $3(17,6 \%)$ & $14(63,6 \%)$ & $4(66,7 \%)$ & $22(40 \%)$ \\
\hline Normal & $9(90 \%)$ & $14(82,4 \%)$ & $8(36,4 \%)$ & $2(33,3 \%)$ & $33(60 \%)$ \\
\hline $\begin{array}{c}\text { Abdominal } \\
\text { Circunference }\end{array}$ & \multicolumn{5}{|c|}{$p=0,089$} \\
\hline High & $1(10 \%)$ & $2(11,8 \%)$ & $8(36,4 \%)$ & - & $11(20 \%)$ \\
\hline Normal & $9(90 \%)$ & $15(88,2 \%)$ & $14(63,6 \%)$ & $6(100 \%)$ & $44(80 \%)$ \\
\hline Glucose & \multicolumn{5}{|c|}{$p=0,008$} \\
\hline High & - & $2(11,8 \%)$ & $8(36,4 \%)$ & $4(66,7 \%)$ & $14(25,5 \%)$ \\
\hline Normal & $10(100 \%)$ & $15(88,2 \%)$ & $14(63,6)$ & $2(33,3 \%)$ & $41(74,5 \%)$ \\
\hline Total, Cholesterol & \multicolumn{5}{|c|}{$p=0,027$} \\
\hline High & $1(10 \%)$ & - & $6(27,3 \%)$ & $3(50 \%)$ & $10(18,5 \%)$ \\
\hline Normal & $9(90 \%)$ & 17 (100\%) & $16(72,7 \%)$ & $3(50 \%)$ & $45(81,5 \%)$ \\
\hline HDL & \multicolumn{5}{|c|}{$\mathbf{p}=\mathbf{0 , 0 1 7}$} \\
\hline Low & $1(10 \%)$ & $1(6,25 \%)$ & $10(45,5 \%)$ & $3(50 \%)$ & $15(27,8 \%)$ \\
\hline Normal & $9(90 \%)$ & $16(93,75)$ & $12(54,5 \%)$ & $3(50 \%)$ & $40(72,2 \%)$ \\
\hline Triglycerides & \multicolumn{5}{|c|}{$p=0,078$} \\
\hline High & $1(10 \%)$ & $4(23,5 \%)$ & $9(40,9 \%)$ & $4(66,7 \%)$ & $18(32,7 \%)$ \\
\hline Normal & $9(90 \%)$ & $13(76,5 \%)$ & $13(59,1 \%)$ & $2(33,3 \%)$ & $37(67,3 \%)$ \\
\hline
\end{tabular}

Table 5: Frequency of Metabolic Syndrome in the patients in the study.

\begin{tabular}{|c|c|c|c|}
\hline \multirow{3}{*}{ Variable } & \multicolumn{2}{|c|}{ Metabolic Syndrome } & \multirow{3}{*}{ Total, sample $=55$} \\
\hline & Non Present & Present & \\
\hline & $n=29$ & $n=26$ & \\
\hline Sex & \multicolumn{3}{|c|}{$p=0,324$} \\
\hline Women & $15(51.72 \%)$ & $10(38,46 \%)$ & $25(45,45 \%)$ \\
\hline Men & $14(48,27 \%)$ & $16(61,54 \%)$ & $30(54,55 \%)$ \\
\hline Age & \multicolumn{3}{|c|}{$p=0,0001$} \\
\hline \multirow{2}{*}{ Average* } & $36 \pm 15$ & $63 \pm 7$ & $49 \pm 18$ \\
\hline & $(15-73)$ & $(44-77)$ & $(15-77)$ \\
\hline$\leq 30$ & $12(41,38 \%)$ & $0(0)$ & $12(21,81 \%)$ \\
\hline $31-50$ & $12(41,38 \%)$ & $2(7,7 \%)$ & $14(25,45 \%)$ \\
\hline $51-60$ & $2(6,9 \%)$ & $11(42,30 \%)$ & $13(23,63 \%)$ \\
\hline$>60$ & $3(10,34 \%)$ & $13(50 \%)$ & $16(29,1 \%)$ \\
\hline
\end{tabular}

\section{Discussion}

This work is given under the lack of studies in our country on the area, cardiovascular risk very often complicates patients with and without psoriasis. The main causes of death in the world are cardiovascular conditions derived from the presence of metabolic syndrome and that is why the relevance of carrying out this study was analyzed. In our study, it was observed that the sample was composed of 55 patients distributed and classified in 4 categories according to the PASI, the frequency by gender showed a greater distribution for the male gender compared to the female, which is consistent with prevalence studies for the disease [19]. The findings of our study showed that the Moderates forms were the most frequent of the 4 categories, this finding does not correlate with what was found in studies with similar characteristics and could be due to the lack of timely therapy for reasons already known to all of us. The modifiable and non-modifiable cardiovascular risk factors 
of the patients were evaluated, the main modifiable cardiovascular risk factor was Smoker, this finding agrees with that reflected in other studies [20], where a higher prevalence of Smoker in patients with a diagnosis of Psoriasis. Regarding non-modifiable cardiovascular risk factors, a high presence of Hypertension and Diabetes was observed in the study members, this finding from this study agrees with that found in other investigations [21].

The ATP-III criteria were applied to the study patients, since there is a high frequency of them, especially for Arterial Hypertension, hypertriglyceridemia, and low HDL levels, this finding agrees with what was found in other studies [22]. The frequency of metabolic syndrome was observed in 26 of the 55 patients, which reveals a great similarity in relation to what was found in other studies [23], where higher rates of it have been correlated compared to the general population. Additionally, it was evidenced that the evolution time of Psoriasis was decisive for the appearance of metabolic syndrome with a value of $p=0.001$, various studies have correlated this with the chronic activation of the immune system and the increased expression of pro-inflammatory substances that generate dysfunction. Endothelial and increased burden of cardiovascular disease [24]. The cardiovascular risk assessment when applying the Framingham and GLOBORISK scales showed a high correlation between the PASI severity index and a higher risk score for both scales. This result has been found in investigations where a greater load of cardiovascular disease and a poorer control of Psoriasis [25] have been correlated, which is also influenced by the limited availability of therapeutics at present.

\section{Recommendations}

1. Extend medium and long-term follow-up, to assess cardiovascular risk in patients with Psoriasis.

2. Measure the effects of lack of treatment in patients with Psoriasis and its repercussions regarding cardiovascular risk.

3. Expand the sample of patients including patients with other pathologies of a rheumatological nature to characterize their cardiovascular risk profile and the frequency of metabolic syndrome.

4. Sensitize the staff of the Dermatology service regarding the high rate of cardiovascular disease in these patients.

5. Generate directives with the Hospital Management to acquire the necessary medications for the management of these patients.

6. Implement cardiovascular risk prevention programs in patients who come to the Psoriasis clinic.

7. Establish in the clinical practice of the Dermatology Service tools to assess cardiovascular risk annually and request tests according to that risk.
8. Continue with research related to cardiovascular risk and psoriasis.

9. Timely refer patients with Psoriasis and other Comorbidities to the relevant service.

10. Use stratification tools such as Framingham and GLOBORISK in the evaluation of cardiovascular risk.

\section{References}

1. Van Nuffel E, Afonina IS, Beyaert R (2018) Psoriasis Plays a Wild CARD. J Invest Dermatol 138(9): 1903-1905.

2. Groot J, Nybo Andersen AM, Adam A, Tind Nielsen TE, Blegvad C, et al. (2019) Associations between maternal socioeconomic position and psoriasis: A cohort study among the offspring of the Danish National Birth Cohort. Br J Dermatol 180(2): 321-328.

3. Jorge MA, Gonzaga HFS, Tomimori J, Picciani BLS, Barbosa CA (2017) Prevalence and heritability of psoriasis and benign migratory glossitis in one Brazilian population. A Bras Dermatol 92(6): 816-819.

4. Argote A, Mora Hernández O, Milena Aponte L, Barrera Chaparro DI, Muñoz Ruiz LM, et al. (2017) Cardiovascular Risk Factors and Carotid Intima-Media Thickness in a Colombian Population with Psoriasis. Actas Dermosifiliogr 108(8): 738-745.

5. Schulte DM, Paulsen K, Türk K, Brandt B, Freitag Wolf S, et al. (2018) Small dense LDL cholesterol in human subjects with different chronic inflammatory diseases. Nutr Metab Cardiovasc Dis 28(11): 1100-1105.

6. Kirby B, Lynch M (2018) Adipokines and psoriasis: The obesity link. Br J Dermatol 179(2): 273-281.

7. Jia A, Xu S, Xing Y, Zhang W, Yu X, et al. (2018) Prevalence and cardiometabolic risks of normal weight obesity in Chinese population: A nationwide study. Nutr Metab Cardiovasc Dis 28(10): 1045-1053.

8. Mandecka A, Regulska Ilow B (2018) Dietary interventions in the treatment of metabolic syndrome as a cardiovascular disease riskinducing factor. A review Rocz Panstw Zakl Hig 69(3): 227-233.

9. Fingeret M, Marques Vidal P, Vollenweider P (2018) Incidence of type 2 diabetes, hypertension, and dyslipidemia in metabolically healthy obese and non-obese. Nutr Metab Cardiovasc Dis 28(10): 1036-1044.

10. Tahergorabi Z, Moodi M, Zardast M, Ghayravani Z, Tavakoli T (2018) Metabolic Syndrome and the Risk of Gastrointestinal Cancer: A CaseControl Study. Asian Pac J Cancer Prev 19(8): 2205-2210.

11. Ferdinando LB, Fukumoto PK, Sanches S, Fabricio LHZ, Skare TL (2018) Metabolic syndrome and psoriasis: A study in 97 patients. Rev Assoc Med Bras 64(4): 368-373.

12. Espósito RC, De Medeiros PJ, Silva FS, Oliveira AG, Soares Aragão CF, et al. (2018) Prevalence of the metabolic syndrome according to different criteria in the male population during the Blue November Campaign in Natal, RN, Northeastern Brazil. Diabetes Metab Syndr Obes 11: 401-408.

13. Gutiérrez Solis AL, Datta Banik S, Méndez González RM (2018) Prevalence of Metabolic Syndrome in Mexico: A Systematic Review and Meta-Analysis. Metab Syndr Relat Disord 16(8): 395-405.

14. Nieto Martínez R, González Rivas JP, Ugel E, Brajkovich I, Risquez A, et al. (2018) Application of the Aace/Ace Advanced Framework for the Diagnosis of Obesity and Cardiometabolic Disease Staging in a General Population From 3 Regions of Venezuela: The Vemsols Study Results. Endocr Pract 24(1): 6-13.

15. Phan C, Touvier M, Kesse Guyot E, Adjibade M, Hercberg S, et al. (2018) Association Between Mediterranean Anti-inflammatory Dietary Profile and Severity of Psoriasis: Results from the NutriNet-Santé Cohort. JAMA Dermatol 154(9): 1017-1024. 
16. Polic MV, Miskulin M, Smolic M, Kralik K, Miskulin I, et al. (2018) Psoriasis Severity-A Risk Factor of Insulin Resistance Independent of Metabolic Syndrome. Int J Environ Res Public Health 15(7): 1486.

17. Gulliver WP, Randell S, Gulliver S, Macdonald D, Gregory V, et al. (2019) An Investigation of Comorbid Disease and Health Service Utilization Among Patients with Moderate to Severe Psoriasis in Newfoundland and Labrador. J Cutan Med Surg 23(1): 29-34.

18. Issue Information-Declaration of Helsinki (2019) J Bone Miner Res 34(3): BMi-BMii.

19. Groot J, Nybo Andersen AM, Adam A, Tind Nielsen TE, Blegvad C, et al. (2019) Associations between maternal socioeconomic position and psoriasis: A cohort study among the offspring of the Danish National Birth Cohort. Br J Dermatol 180(2): 321-328.

20. Armstrong AW, Harskamp CT, Dhillon JS, Armstrong EJ (2014) Psoriasis and smoking: A systematic review and meta-analysis. Br J Dermatol 170(2): 304-314.

21. Morici N, Ferri LA, Alicandro G, Tortorella G, Tondi S, et al. (2018) Psoriasis and the risk of acute coronary syndrome in the elderly. Int J Cardiol 273: 44-46.
22. Rodríguez Zúñiga MJM, Cortez Franco F, Quijano Gomero E (2017) Association of Psoriasis and Metabolic Syndrome in Latin America: A Systematic Review and Meta-Analysis. Actas Dermosifiliogr 108(4): 326-334.

23. Kothiwala SK, Khanna N, Tandon N, Naik N, Sharma VK, et al. (2016) Prevalence of metabolic syndrome and cardiovascular changes in patients with chronic plaque psoriasis and their correlation with disease severity: A hospital-based cross-sectional study. Indian J Dermatol Venereol Leprol 82(5):510-518

24. Morici N, Ferri LA, Alicandro G, Tortorella G, Tondi S, et al. (2018) Psoriasis and the risk of acute coronary syndrome in the elderly. Int J Cardiol 273: 44-46.

25. Caiazzo G, Fabbrocini G, Di Caprio R, Raimondo A, Scala E, et al. (2018) Psoriasis, Cardiovascular Events, and Biologics: Lights and Shadows. Front Immunol 9: 1668

\section{(c) (1) \\ This work is licensed under Creative Commons Attribution 4.0 License}

To Submit Your Article Click Here:

Submit Article

DOI: 10.32474/ACR.2020.03.000151

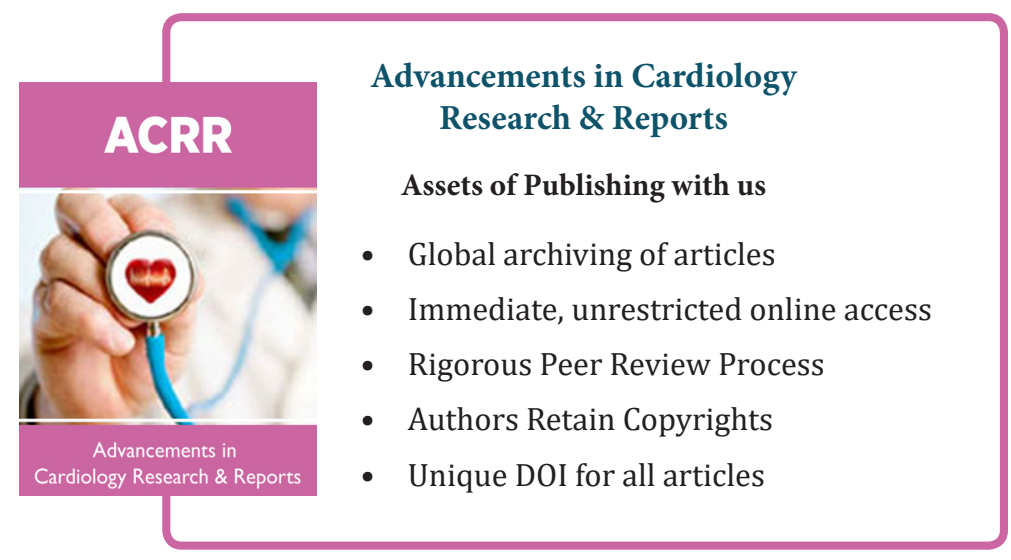

